\title{
PENGARUH CITY BRANDING PADA CITY IMAGE DAN KEPUTUSAN BERKUNJUNG WISATAWAN KE KABUPATEN PURWAKARTA
}

\author{
Jesi Indriani \\ Chandra Kuswoyo
}

Universitas Kristen Maranatha Bandung

Email: chandrakuswoyo@yahoo.com

Submitted: Feb 3, 2016; Reviewed: Feb 3, 2016; Accepted: June 10, 2017

\begin{abstract}
This research aims to investigate the influence of city branding on city image, investigate the influence of city branding on decision to visit, and investigate the influence of city image on decision to visit. The research method used in this study is explanatory research. Sample of 156 tourist visiting the tourist attractions in Purwakarta. Method of data is collection questionnaire, causal explanatory, and using Path Analysis. The result showed that city branding variable $(X)$ significantly influence on city image $\left(Y_{1}\right)$ about $40,7 \%$, city branding variable $(X)$ significantly influence on decision to visit $\left(Y_{2}\right)$ about $11,5 \%$, city image variable $\left(Y_{1}\right)$ significantly influence on decision to visit $\left(Y_{2}\right)$ about 19,5\%, and also city branding variables $(X)$ and city image variable $\left(Y_{1}\right)$ significantly influence on decision to visit $\left(Y_{2}\right)$ about 50,20\%. The conclusion of this research is a significant effect on city branding impact city image and decision to visit Purwakarta city.
\end{abstract}

Keywords: city branding, city image, and decision to visit.

\section{PENDAHULUAN}

Indonesia memiliki banyak potensi wilayah pariwisata, baik yang sudah cukup dikenal di luar negeri maupun yang belum dikenal wisatawan lokal. Untuk memperkenalkan suatu daerah obyek wisata di berbagai wilayah Indonesia, maka pemerintah pusat khususnya pemerintah masing-masing daerah harus memiliki strategi yang tepat untuk memperkenalkannya kepada wisatawan lokal maupun wisatawan mancanegara karena bagaimana pun juga pariwisata adalah salah satu penyumbang pendapatan devisa yang cukup besar di luar ekspor migas yaitu sekitar 4\% dari total PDB (pendapatan domestik bruto) serta hampir 9\% dari total angkatan kerja nasional dipekerjakan di sektor pariwisata (www.indonesiainvestmenst.com). Pemerintah ingin meningkatkan angka ini menjadi dua kali lipat menjadi $8 \%$ dari PDB, sebuah target yang ambisius dan tentu saja ini mustahil bisa tercapai tanpa dukungan juga dari pemerintah masingmasing daerah yang memiliki potensi wisata yang menjanjikan.

Dalam UU No.21 tahun 1999 yang kemudian disempurnakan dengan UU No. 32
Tahun 2004 mengenai peraturan daerah yang berisi otonomi daerah mulai mengeksplorasi potensi daerah yang dimiliki. Otonomi daerah diarahkan untuk mempercepat terwujudnya kesejahteraan masyarakat melalui peningkatan, pelayanan, pemberdayaan, dan partisipasi masyarakat, serta peningkatan daya saing daerah dengan memperhatikan potensi dan keragaman daerah, peluang, serta persaingan global. Pemerintah daerah harus meningkatkan kemampuannya dalam mengumpulkan Pendapatan Asli Daerah (PAD) dengan maksud agar subsidi dari pemerintah pusat dapat diperkecil serta mengurangi beban APBN. Oleh sebab itu, beberapa kota di Indonesia mulai membuat strategi pemasaran untuk menarik minat wisatawan agar berkunjung ke kota tersebut.

Masing-masing daerah berusaha memaksimalkan jumlah kunjungan wisatawan, tak terkecuali juga terjadi pada daerah Purwakarta yang sejak 13 Maret 2008 dipimpin oleh Dedi Mulyadi mengalami perkembangan pesat di segala sektor khususnya sektor pariwisata. Kabupaten Purwakarta bersaing ketat juga dengan daerah-daerah lain di Indonesia 
dalam hal menarik minat wisatawan baik lokal maupun wisatawan mancanegara (wisman). Saat ini memang kota Purwakarta belum berada dalam 5 besar kota yang diminati wisman (Yogyakarta, Makassar, Denpasar, Jakarta, dan Medan) berdasarkan sumber www.hipwee.com (11 April 2015), sehingga ini menjadi tugas berat bagi pemerintah kabupaten Purwakarta untuk berdiri sejajar dengan kota-kota tersebut. Saat ini, sedikitnya 20 ribu orang berkunjung pada hari Sabtu ke Kabupaten Purwakarta. Kunjungan terbanyak masyarakat adalah ke tempat lokal wisata kuliner seperti sate Maranggi dan juga ikon baru Taman Wisata Mancur Sri Baduga yang berada di kawasan Situ Buleud. Di tahun 2016 ini Pemkab Purwakarta terus menggenjot pertumbuhan tingkat wisatawan yang datang menjadi sedikitnya 3 juta orang khususnya wisawatan domestik (www.detiknews.com, Februari 2016).

Potensi daerah khususnya bidang pariwisata yang begitu besar tapi tanpa didasari perencanaan dan pelaksanaan strategi yang tepat maka tujuan tidak akan tercapai dengan maksimal. Salah satu strategi pemasaran yang bisa diterapkan untuk memaksimalkan potensi daerah bahkan membentuk 'brand image' di benak wisatawan adalah melakukan 'Place Branding atau City Branding' (Wandari L A, 2014). City branding merupakan manajemen citra suatu destinasi melalui inovasi strategis serta koordinasi ekonomi, sosal, komersial, budaya, dan peraturan pemerintah (Simon Anholt dalam Moilanen \& Rainisto, 2009).

Beberapa kota di Indonesia mengadopsi strategi city branding untuk mempromosikan potensi pariwisatanya. Beberapa kota yang sudah menerapkan city branding diantanya adalah kota Solo dengan "Spirit of Java". Yogyakarta dengan "Never Ending Asia", termasuk juga Jakarta dengan "Enjoy Jakarta" (Wandari, 2014). Selain kota-kota di atas yang memiliki city branding, Purwakarta juga menerapkan city branding yaitu "PURWAKARTA ISTIMEWA". Purwakarta selama ini dikenal sebagai titik temu tiga koridor utama lalu lintas yaitu JakartaPurwakarta, Purwakarta-Bandung, dan Purwakarta-Cirebon. Letak Purwakarta yang strategis tersebut menjadikan Purwakarta mudah diakses oleh masyarakat dari luar Purwakarta. Terlebih lagi sejak pembangunan tol Cipularang dan rel kereta double track mulai berfungsi serta pembangunan sektor industri dan budaya mulai dilakukan, menjadikan daerah Purwakarta memiliki daya tarik sendiri bagi wisatawan yang 42 berkunjung ke Purwakarta. Daya tarik yang dibangun oleh pemerintah daerah sehingga menghasilkan diferensiasi dari daerah lain menjadikan Purwakarta daerah yang istimewa bagi masyarakat purwakarta maupun wisatawan lokal dan internasional, sehingga pemerintah daerah Purwakarta memilih brand "PURWAKARTA ISTIMEWA". Beberapa destinasi wisata maupun keunikan yang dimiliki Kabupaten Purwkarta yang membuat daerah ini 'istimewa" antara lain: Sate Maranggi Cibungur sebagai salah satu wisata kuliner yang sudah terkenal sejak lama, waduk Jatiluhur yang merupakan waduk buatan pertama di Indonesia yang dibangun pada tahun 1957, Jatiluhur Waterworld yang lokasinya berada di kawasan Waduk Jatiluhur, Giri Tirta Kahuripan sebagai tempat wisata keluarga, Taman air mancur Sri Baduga Situ Buleud di atas danau seluas 4 hektar, dan masih banyak destinasi menarik lainnya (www.nativeindonesia.com). Dengan adanya city branding tersebut diharapkan akan membentuk city image yang akan mampu menarik minat berkunjung wisatawan ke Purwakarta, dimana city image yang diharapkan adalah city image yang positif sehingga dapat meningkatkan minat berkunjung wisatawan.

Berdasarkan latar belakang masalah tersebut maka tujuan penelitian ini adalah untuk mengetahui Pengaruh City Branding "Purwakarta Istimewa" pada City Image dan Keputusan Berkunjung Wisatawan ke Kabupaten Purwakarta. Adapun manfaat dari penelitian ini diharapkan dapat menjadi masukan sebagai bahan acuan dan pertimbangan dalam menentukan strategi-strategi pemerintah khusunya pemerintah daerah Purwakarta untuk meningkatkan jumlah kunjungan wisatawan khususnya dalam jangka pendek ini adalah meningkatnya jumlah kunjungan wisatawan domestik melalui strategi city branding yang tepat.

\section{KERANGKA TEORITIS DAN PERUMUSAN HIPOTESIS \\ City Branding}

City branding merupakan bagian dari perencanaan kota/perkotaan melalui berbagai upaya untuk membangung differensiasi dan memperkuat identitas kota lainnya demi menarik turis, penanaman modal, sumber daya manusia yang andal, industri, serta meningkatkan kualitas hubungan antara warga dengan kota (Yananda \& Salamah, 2014). City branding adalah upaya 
memberikan merek kepada kota agar mudah dikenali dan dapat membentuk city image untuk memasarkan daerah baik secara lokal maupun internasional (Jannah, 2014).

Mengukur efektivitas city branding dapat menggunakan city branding hexagon yang diciptakan oleh Simon Anholt (2007) yang terdapat enam aspek dalam pengukuran efektivivitas city branding terdiri atas:

1. Presence (kehadiran)

Pandangan pengunjung terhadap status dan reputasi internasional kotanya tersebut secara global. Pengunjung akan mengenal suatu kota dengan melakukan suatu perjalanan atau mengunjunginya. Pasar yang lebih efektif kemungkinan akan melihat potensi dan keunikan apa yang dapat ditawarkan kota tersebut serta dapat memenuhi harapan mereka.

2. Potential (potensial)

Mempertimbangkan peluang-peluang internal atau pun eksternal kota, misalnya apakah tempat tersebut cocok untuk berbisnis atau menjadi kota tujuan wisata.

3. Place (tempat)

Menyelidiki presepsi orang-orang tentang aspek fisik setiap kota yang berkaitan dengan kenyamanan iklim, kebersihan lingkungan dan seberapa menariknya bangunan dan tamannya.

4. People (orang)

Mengungkapkan bagaimana karakter penduduk kota tersebut apakah akan ramah tamah, dan apakah pengunjung akan mudah bagi mereka menemukan dan cocok membaur ke dalam sebuah komunitas yang berbagi tentang bahasa dan budaya mereka.

5. Pulse (semangat)

Menentukan jika terdapat hal-hal daya tarik yang berhubungan dengan mengisi waktu kosong dan betapa menariknya kota tersebut berkaitan dengan hal baru untuk dicari.

6. Prerequisite (prasyarat)

Hal penting yang harus diperhatikan dari suatu kota yaitu fasilitas pendukung kegiatan pengunjung. Fasilitas tersebut menjadi prasyarat utama dalam pengembangan suatu kota karena fasilitas tersebut merupakan alat bagi wisatawan dalam menentukan bagaimana orang-orang menerima kualitas-kualitas dasar kota, apakah kota tersebut memuaskan, menghasilkan, mengakomodasikan, seperti standar infrastruktur publiknya, aksesibilitas, event, dan fasilitas pendukung lainnya.

Beberapa keuntungan bagi para pemangku kepentingan dengan melakukan city branding menurut Handito (dalam Sugiarsono, 2009):

1. Memperkenalkan kota/daerah lebih dalam

Penerapan city branding, suatu kota akan memperkenalkan dirinya lebih dalam, karena pihak eksternal harus mengetahui keberadaan suatu kota. Yang pada akhirnya kemudian peningkatan kunjungan terhadap suatu kota semakin tinggi.

2. Memperbaiki citra

Citra suatu kota yang sudah dinilai buruk oleh pengunjung maupun penduduk kota sendiri, cukup sulit suatu kota memiliki daya tarik bagi pihak yang berkepentingan, namun salah satu strategi mengembalikan citra positif kota yaitu dengan city branding yang diimbangi dengan implementasi komprehensif, maka akan meningkatkan daya tarik kota sebgai tujuan para pemangku kepentingan.

3. Menarik wisatawan asing dan domestik Penerapan city branding yang tepat dapat menarik pemangku kepentingan eksternal kota termasuk wisatawan domestik maupun asing, hal ini dikarenakan wisatawan memandang merek merupakan pembeda satu dengan yang lainyya sehingga akan memilih suatu tempat dengan keunikan atau citi khas yang tidak dimiliki kota lain.

4. Menarik minat investor untuk berinvestasi Tujuan lain dari city branding untuk mendapatkan investasi guna meningkatkan pengembangan kota baik itu dari sector ekonomi, sosial atau yang lainnya.

5. Meningkatkan perdagangan

Melalui penerapan city brand suatu kota akan dikenal luas oleh masyarakat baik itu di dalam negeri ataupun di luar negeri. Maka akan tercipta suatu transaksi yang dilakukan oleh pihak eksternal kota maupun pihak internal kota yang menyebabkan terjadinya peningkatan perdagangan.

\section{City Image}

City Image merupakan citra suatu kota yang terbentuk di benak masyarakat karena adanya ciri khas dari kota tersebut (Jannah, 2014). Menurut Kenneth Boulding (Avraham, 2008 dalam Yananda, dkk, 2014), citra tempat adalah 
sekumpulan karakteristik tempat yang inheren dengan perspektif manusianya. Boulding (2008) membagi citra tempat berdasarkan empat komponen, yaitu:

1. Kognitif (apa yang diketahui seseorang tentang suatu tempat)

2. Afektif (bagaimana perasaan seseorang terkait tempat tertentu)

3. Evaluative (bagaimana evaluasi seseorang terhadap suatu tempat atau tempat tinggalnya)

4. Behavioral (apakah seseorang mempertimbangkan untuk berimigrasi/bekerja/berkunjung/ berivestasi pada tempat tertentu)

Keputusan Berkunjung

Pada dasarnya keputusan berkunjung adalah keputusan yang diambil oleh seseorang sebelum mengunjungi suatu tempat atau wilayah dengan mempertimbangkan beberapa faktor (Jannah, 2014). Indikator yang menentukan minat berkunjung menurut Ferdinand (2002):

1) Ketertarikan produk, yaitu konsumen memiliki kecenderungan membeli atau mengiginkan suatu produk yang berbeda dari produk yang lain.

2) Price, minat price yaitu tertariknya konsumen dengan harga yang ditawarkan, sesuai dengan biaya yang dimiliki konsumen dan anatara harga dengan fasilitas yang ditawarkan sesuai.

3) Minat pelayanan dan fasilitas adalah sarana dan prasana pendukung pariwisata yang ditawarkan terhadap konsumen, sehingga konsumen berminat untuk melakukan perjalanan pariwisata.

4) Preferensial, minat preferensial memiliki fokus utama pada suatu produk tertentu. Minat Preferensial memiliki dapat berubah apabila produk yang telah menjadi fokus utama mengalami perubahan atau terjadi sesuatu yang tidak lagi sesuai dengan minat konsumen.

5) Informasi, pengunjung lebih mudah mendapatkan info tentang produk atau tujuan wisata.

6) Referensial, adalah konsumen yang tertarik dengan produk tertentu atau tujuan wisata tertentu karena mendapatkan referensi dari konsumen lain.

Hubungan antara City Branding dengan City Image dan Keputusan Berkunjung

Penerapan city branding pada suatu destinasi wisata akan berpengaruh terhadap keputusan 44 wisatawan untuk mengunjungi suatu objek wisatadi daerah tersebut. Kota yang sudah memiliki branding atau merek akan memiliki citra tersendiri bagi wisatawan karena memiliki ciri khas yang membedakan dengan kota-kota lain sehingga memberikan kenangan yang berbeda. Selain itu, adanya branding pada suatu kota memiliki tujuan untuk meningkatkan kunjungan wisatawan terhadap objek wisata yang ada di Kabupaten Purwakarta. Ketika city image sudah terbentuk di suatu daerah maka diharapkan akan mampu menjadikan daerah tersebut sebagai daerah tujuan wisata (Jannah, Bridiatul, dkk; 2014).

\section{Model Penelitian}

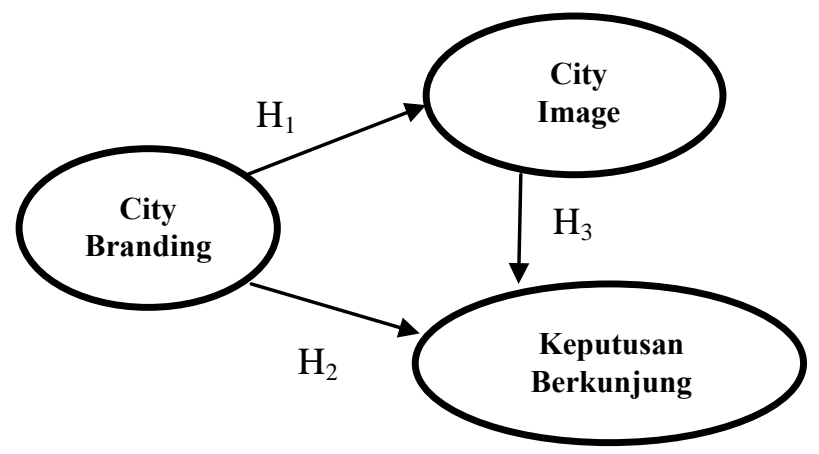

Gambar 1 Model Penelitian Yang Dihipotesiskan

\section{Pengembangan hipotesis}

Pengaruh City Branding terhadap City Image Menurut Kavaratzis (2008) city branding umumnya memfokuskan pada pengelolaan citra (image), tepatnya apa dan bagaimana citra itu akan dibentuk serta aspek komunikasi yang dilakukan dalam proses pengelolaan citra (image). Jannah., Arifin \& Kusumawati (2014) menemukan bahwa city branding berpengaruh signifikan terhadap city image. Hasil temuan tersebut juga sesuai dengan hasil penelitian Wandari., Kumandji \& Kusumawati (2014). Berdasarkan pada uraian dan hasil temuan penelitian-penelitian sebelumnya, hipotesis yang diusulkan pada penelitian ini adalah:

$\mathrm{H}_{1}$ : City Branding berpengaruh terhadap City Image

\section{Pengaruh City Branding pada Keputusan Berkunjung wisatawan}

City Branding akan menjadi "sesuatu" yang menarik bagi calon konsumen. City Branding pada dasarnya adalah janji sebuah kota untuk memberikan sesuatu kepada konsumen. Menurut Kotler dan Armstrong (2004) titik awal 
pengambilan keputusan pembelian adalah model rangsangan dan tanggapan dari perilaku membeli konsumen. Jannah., Arifin \& Kusumawati (2014) menemukan bahwa city branding berpengaruh signifikan terhadap keputusan berkunjung. Hasil temuan tersebut juga sesuai dengan hasil penelitian Wandari., Kumandji \& Kusumawati (2014). Berdasarkan pada uraian dan hasil temuan penelitian-penelitian sebelumnya, hipotesis yang diusulkan pada penelitian ini adalah:

$\mathrm{H}_{2}$ : City Branding berpengaruh terhadap Keputusan Berkunjung wisatawan

\section{Pengaruh City Image terhadap Keputusan Berkunjung wisatawan}

Sebuah destinasi wisata dapat dipandang sebagai campuran dari produk individu dan pengalaman yang bergabung untuk membentuk pengalaman total daerah yang dikunjungi (Murphy dalam Ekinci, 2006). Penelitian sebelumnya telah menunjukkan bahwa image destinasi memiliki komponen kognitif dan afektif (Kotler dalam Ekinci, 2006). Jannah., Arifin \& Kusumawati (2014) menemukan bahwa city image berpengaruh tetapi tidak signifikan terhadap keputusan berkunjung. Hasil temuan tersebut juga sesuai dengan hasil penelitian Wandari., Kumandji \& Kusumawati (2014). Berdasarkan pada uraian dan hasil temuan penelitianpenelitian sebelumnya, hipotesis yang diusulkan pada penelitian ini adalah:

$\mathrm{H}_{3}$ : City Image berpengaruh terhadap Keputusan Berkunjung wisatawan

\section{METODE PENELITIAN}

Penelitian ini bertujuan untuk menguji dan menganalisis pengaruh city branding pada city image dan keputusan berkunjung wisatawan di kota Purwakarta. Berdasarkan tujuan penelitian maka jenis penelitian ini adalah Causal Explanatory karena dalam penelitian ini menjelaskan hubungan antara variabel dan pengujian hipotesis yang telah dirumuskan sebelumnya dan bertujuan untuk menjelaskan berbagai kejadian dan fenomena penelitian. Dalam penelitian ini peneliti menggunakan city branding sebagai variabel independen, city image sebagai variabel intervening, dan keputusan berkunjung sebagai variabel dependen.

\section{Populasi dan Sampel}

Populasi dalam penelitian ini adalah wisatawan yang berkunjung ke Kabupaten Purwakarta dengan kriteria wisatawan domestik yang pernah berkunjung ke Purwakarta sebanyak dua kali atau lebih.

Penentuan jumlah sampel minimum dilakukan berdasarkan perhitungan dengan rumus (Maholtra,1999):

$$
\mathrm{n} \geq \frac{z_{Q}^{2} \cdot p(1-p)}{b^{2}}
$$

Keterangan:

$$
\begin{aligned}
& \mathrm{n}=\text { jumlah sampel yang dibutuhkan } \\
& \mathrm{Z}=\text { bilangan unit standar error dari } \\
& \text { distribusi normal yang akan } \\
& \text { menghasilkan tingkat kepercayaan } \\
& \text { yang diingikan. } \\
& \mathrm{A} \text { tingkat signifikansi } \\
& \mathrm{p} \quad \text { proporsi populasi yang akan } \\
& \text { diteliti (jika tidak dapat } \\
& \text { memperkirakan proporsi populasi } \\
& \text { gunakan p }=0,5 \text { ) } \\
& \mathrm{b} \quad \text { tingkat error atau perbedaan } \\
& \\
& \text { maksimum antara proporsi sampel } \\
& \text { dengan proporsi populasi yang } \\
& \text { dapat diterima dengan tingkat } \\
& \text { kepercayaan yang ditetapkan. }
\end{aligned}
$$

Dalam penelitian ini akan menggunakan tingkat signifikansi $(\alpha) 5 \%$, tingkat kepercayaan $95 \%$ (Z $=1,96)$ dengan error sebesar $10 \%$ sehingga besarnya sampel minimal adalah:

$$
\begin{aligned}
& \mathrm{n} \geq \frac{(1,96)^{2} \cdot 0,5(1-0,5)}{(0,1)^{2}} \\
& \mathrm{n} \geq 96,04=97
\end{aligned}
$$

Setelah mempertimbangkan kemungkinan jumlah kuesioner yang tidak kembali dan yang tidak sah, maka jumlah kuesioner yang disebarkan adalah sebanyak 200 buah (tingkat ketelitian jauh lebih baik). Diharapkan dengan pembagian kuesioner tersebut dapat mewakili gambaran preferensi konsumen.

Gambaran responden pada penelitian ini adalah usia didominasi oleh pria (76\%), dengan usia antara 18-25 tahun (42\%), mempunyai pekerjaan sebagai pegawai swasta $(51 \%)$, pendapatan per bulan responden didominasi dengan pendapatan per bulan di atas Rp 3.000.000,00 yaitu sebesar $55 \%$. Responden yang paling banyak berkunjung adalah wisatawan dari wilayah Bekasi (36\%) dan wilayah Jakarta (22\%). 
Tabel 1 Definisi Operasional Variabel

\begin{tabular}{|c|c|c|c|}
\hline Variabel & $\begin{array}{l}\text { Definisi } \\
\text { Operasional }\end{array}$ & Indikator & Skala \\
\hline $\begin{array}{l}\text { City } \\
\text { Branding }\end{array}$ & $\begin{array}{l}\text { Upaya untuk } \\
\text { memberikan } \\
\text { merek kepada } \\
\text { kota agar mudah } \\
\text { dikenali dan } \\
\text { dapat } \\
\text { membentuk city } \\
\text { image untuk } \\
\text { memasarkan } \\
\text { daerah baik } \\
\text { secara lokal } \\
\text { maupun } \\
\text { internasional } \\
\text { (Jannah, 2014) }\end{array}$ & $\begin{array}{ll}\text { - } & \text { Kehadiran } \\
\text { - } & \text { Potensi } \\
\text { - } & \text { Tempat } \\
\text { - } & \text { Semangat } \\
\text { - } & \text { Orang } \\
\text { - } & \text { Prasyarat }\end{array}$ & Ordinal \\
\hline City Image & $\begin{array}{l}\text { Citra suatu kota } \\
\text { yang terbentuk } \\
\text { di benak } \\
\text { masyarakat } \\
\text { karena adanya } \\
\text { ciri khas dari } \\
\text { kota tersebut } \\
\text { (Jannah, 2014) }\end{array}$ & $\begin{array}{ll}\text { - } & \text { Kognitif } \\
\text { - } & \text { Afektif } \\
\text { - } & \text { Konatif }\end{array}$ & Ordinal \\
\hline $\begin{array}{l}\text { Keputusan } \\
\text { berkunjung }\end{array}$ & $\begin{array}{l}\text { Keputusan yang } \\
\text { diambil oleh } \\
\text { seseorang } \\
\text { sebelum } \\
\text { mengunjungi } \\
\text { suatu tempat } \\
\text { atau wilayah } \\
\text { dengan } \\
\text { mempertimbang } \\
\text { kan beberapa } \\
\text { faktor (Jannah, } \\
\text { 2014) }\end{array}$ & $\begin{array}{ll}\text { - } & \text { Ketertarikan } \\
\text { produk } \\
\text { - } & \text { Harga } \\
& \text { produk } \\
\text { - } & \text { Minat } \\
& \text { pelayanan } \\
\text { dan fasilitas } \\
\text { - } & \text { Preferensial } \\
\text { - } & \text { Informasi } \\
\text { - } & \text { Referensial }\end{array}$ & Ordinal \\
\hline
\end{tabular}

Teknik dan Prosedur Pengumpulan Data

Teknik pengumpulan data yang digunakan dalam penelitian ini berdasarkan teknik purposive sampling, yaitu teknik pengambilan sampel yang dapat dilakukan dengan kriteria-kriteria tertentu (Sekaran, 2006). Kriteria sampel dalam penelitian ini adalah wisatawan domestikyang berkunjung ke Purwakarta minimal dua kali.Alasan digunakanya purposive sampling karena jumlah populasi yang sangat besar dengan aktivitas responden yang tinggi yaitu orangorang yang pernah berkunjung ke Purwakarta. Pengumpulan data dilakukan dengan metode survei menggunakan kuesioner. Penelitian dilakukan pada bulan Oktober-November 2015 dan didapatkan 156 kuesioner dari 200 kuesioner yang disebar yang memenuhi syarat untuk dapat diolah pada tahap berikutnya.

\section{Teknik Analisis Data}

Teknik analisis data yang digunakan dalam penelitian ini yaitu regresi dengan mediasi/intervening. Regresi intervening adalah variabel mediasi/intervening merupakan variabel antara atau mediating, yang berfungsi memediasi hubungan antara variabel independent (city branding) dengan variabel dependen (city image dan keputusan berkunjung), (Gozali, 2011). Pemilihan teknik analisis data ini ditujukan untuk menjawab hipotesis yang telah diajukan sebelumnya, yakni penelitian ini bertujuan menguji variabel mediasi. Teknik ini dilakukan dengan cara menguji $\left(\mathrm{X}_{1}\right)$ dapat berpengaruh langsung terhadap $(\mathrm{Y})$ dan berpengaruh secara tidak langsung melalui $\mathrm{X}_{2}$, kemudian ke $\mathrm{Y}$. untuk menguji pengaruh variabel intervening digunakan metode analisis jalur (Path Analysis). Menurut Ghozali (2011), analisis jalur (Path Analysis) merupakan penggunaan analisis regresi untuk menaksir hubungan kausalitas antar variabel (model kausal) yang telah ditetapkan sebelumnya berdasarkan teori. Dalam analisis jalur pengaruh independen variabel terhadap dependen variabel dapat berupa pengaruh langsung dan tidak langsung (Juanim, 2004). Adapun model persamaan regresi yang dihasilkan adalah sebagai berikut:

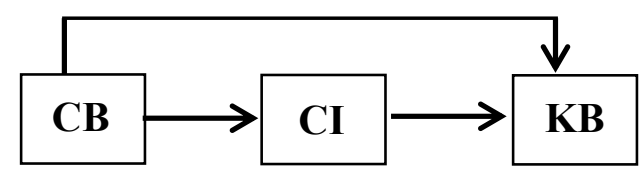

Persamaan Langsung

1. $\mathrm{KB}=\rho_{1} \cdot \mathrm{CB}+\rho_{2} \cdot \mathrm{CI}+\mathrm{e}_{1}$ (regresi berganda)

2. $\mathrm{CI}=\rho_{3} \cdot \mathrm{CB}+\mathrm{e}_{2}$ (regresi sederhana)

Persamaan Tidak langsung

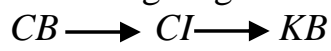

Standardize coefficients pada persamaan no. 1 akan memberikan nilai $\rho_{1}$ dan $\rho_{2}$, sedangkan persamaan no. 2 akan memberikan nilai $\rho_{3}$. Besarnya pengaruh langsung dan tidak langsung menunjukan sebagai berikut:

Pengaruh langsung $\mathrm{CB}$ ke KB $\quad=\rho_{1}$ Pengaruh tidak langsung CB ke CI ke KB $=\rho_{2} \times \rho_{3}$ Total pengaruh (korelasi CB-KB) $=\rho_{1}+\left(\rho_{2} \times \rho_{3}\right)$

Dimana:
$\mathrm{CB}=$ City Branding
$\mathrm{CI}=$ CityImage
$\mathrm{KB}=$ Keputusan Berkunjung
$\rho=$ nilai standardize coefficient
$\mathrm{e}=$ error/tingkat kesalahan (diperoleh dari rumus $\left.\sqrt{ } 1-\sqrt{R^{2}}\right)$ 


\section{Uji Validitas dan Reliabilitas}

Menurut Ghozali (2011), uji validitas digunakan untuk mengukur sah atau valid tidaknya suatu kuesioner. Suatu kuesioner dapat dikatakan valid apabila pertanyaan pada kuesioner mampu untuk mengungkapkan sesuatu yang diukur oleh kuesioner tersebut. Penelitian ini menggunakan pengukuran validitas dengan cara Uji Korelasi Product Moment/Pearson (Analisis Butir). Menurut Suliyanto (2005), uji validitas disini dilakukan dengan cara mengkorelasikan skor pada item dengan skor itemnya. Skor item dianggap sebagai nilai $X$, sedangkan skor total dianggap sebagai nilai Y. Keputusan pada sebuah butir pertanyaan dapat dianggap valid dapat dilakukan dengan berbagai cara:

- Jika koefisien korelasi product moment melebihi 0,361 (Sugiyono, 1999)

- Jika koefisien korelasi product moment> $\mathrm{r}$ tabel $(\mathrm{a} ; \mathrm{n}-2) \mathrm{n}=$ jumlah sampel

- $\quad$ Nilai $\operatorname{sig} \leq \alpha$

Sementara itu, reliabilitas menunjukkan keajegan,kemantapan atau kekonsistenan suatu instrumen penelitian mengukur apa yang hendak diukur.Menurut Sekaran (2006) dalam Hartono (2011), reliabilitas suatu pengukuran menunjukkan stabilitas dan konsistensi dari suatu instrument yang mengukur suatu konsep dan berguna untuk mengakses "kebaikan" dari suatu pengukur.

Suatu variabel dapat dikatakan reliable jika memiliki Cronbach Alpha $\geq 0,7$ atau tingkat kesalahan pengukuran (measurement error) kurang dari 0,51 atau 51\%dan memiliki Cronbach Alpha if item deleted $\leq$ dari Cronbach Alpha (Sekaran, 2006)

\section{HASIL DAN PEMBAHASAN}

Pengujian validitas dalam penelitian ini dilakukan dengan cara mengkorelasikan skor masing-masing pernyataan item yang ditujukan kepada responden dengan total skor untuk seluruh item. Teknik korelasi yang digunakan untuk menguji validitas butir pernyataan dalam penelitian ini adalah korelasi Pearson product moment. Apabila nilai koefisien korelasi butir item pernyataan yang sedang diuji lebih besar dari $r_{\text {tabel }}(n=30) 0,361$, maka dapat disimpulkan bahwa item pernyataan tersebut merupakan konstruksi (construct) yang valid. Adapun hasil uji validitas kuesioner kelima variabel yang diteliti disajikan pada tabel berikut:
Tabel 2 Rekapitulasi Hasil Uji Validitas Sub Variabel City Branding (X)

\begin{tabular}{cccc}
\hline $\begin{array}{c}\text { Item } \\
\text { Pernyataan }\end{array}$ & $\begin{array}{c}\text { Koefisien } \\
\text { Validitas }\end{array}$ & $\begin{array}{c}\text { Titik } \\
\text { Kritis }\end{array}$ & Kesimpulan \\
\hline 1 & 0,458 & 0,361 & Valid \\
2 & 0,550 & 0,361 & Valid \\
3 & 0,539 & 0,361 & Valid \\
4 & 0,503 & 0,361 & Valid \\
5 & 0,684 & 0,361 & Valid \\
6 & 0,486 & 0,361 & Valid \\
7 & 0,556 & 0,361 & Valid \\
8 & 0,657 & 0,361 & Valid \\
9 & 0,596 & 0,361 & Valid \\
10 & 0,613 & 0,361 & Valid \\
11 & 0,547 & 0,361 & Valid \\
\hline
\end{tabular}

Tabel 3 Rekapitulasi Hasil Uji Validitas Sub

\begin{tabular}{llll}
\multicolumn{4}{c}{ Item } \\
Pernyataan & $\begin{array}{c}\text { Koefisien } \\
\text { Validitas }\end{array}$ & $\begin{array}{c}\text { Titik } \\
\text { Kritis }\end{array}$ & Kesimpulan \\
\hline 1 & 0,640 & 0,361 & Valid \\
2 & 0,477 & 0,361 & Valid \\
3 & 0,711 & 0,361 & Valid \\
4 & 0,731 & 0,361 & Valid \\
5 & 0,733 & 0,361 & Valid \\
6 & 0,791 & 0,361 & Valid \\
\hline
\end{tabular}

Tabel 4 Rekapitulasi Hasil Uji Validitas Sub Variabel Keputusan Berkunjung $\left(\mathrm{Y}_{2}\right)$

\begin{tabular}{llll}
\hline $\begin{array}{c}\text { Item } \\
\text { Pernyataan }\end{array}$ & $\begin{array}{c}\text { Koefisien } \\
\text { Validitas }\end{array}$ & $\begin{array}{c}\text { Titik } \\
\text { Kritis }\end{array}$ & Kesimpulan \\
\hline 1 & 0,625 & 0,361 & Valid \\
2 & 0,666 & 0,361 & Valid \\
3 & 0,636 & 0,361 & Valid \\
4 & 0,758 & 0,361 & Valid \\
5 & 0,645 & 0,361 & Valid \\
6 & 0,650 & 0,361 & Valid \\
\hline
\end{tabular}


Pada ketiga tabel di atas dapat dilihat untuk hasil uji validitas yang menunjukkan bahwa terdapat seluruh instrumen penelitian memiliki nilai $r_{\text {hitung }}$ lebih besar dari 0,361, sehingga instrumentinstrumen tersebut dinyatakan valid dan dapat digunakan sebagai alat ukur dalam penelitian ini.

Pengujian reliabilitas dilakukan terhadap butir pernyataan yang termasuk dalam kategori valid. Kuesioner dikatakan andal apabila koefisien reliabilitas bernilai positif dan $\geq 0,70$. Adapun hasil dari uji reliabilitas berdasarkan pada rumus Cronbach Alpha diperoleh hasil sebagai berikut:

\section{Tabel 5}

Rekapitulasi Hasil Uji Reliabilitas Kuesioner Penelitian

\begin{tabular}{cccc}
\hline Variabel & $\begin{array}{c}\text { Koefisien } \\
\text { Reliabilitas }\end{array}$ & $\begin{array}{c}\text { Titik } \\
\text { Kritis }\end{array}$ & Kesimpulan \\
\hline $\begin{array}{c}\text { City } \\
\text { Branding } \\
\text { (X) }\end{array}$ & 0,780 & 0,700 & Reliabel \\
$\begin{array}{c}\text { City } \\
\text { Images } \\
(\mathrm{Y} 1)\end{array}$ & 0,771 & 0,700 & Reliabel \\
$\begin{array}{c}\text { Keputusan } \\
\text { Berkunjung } \\
\text { (Y2) }\end{array}$ & 0,762 & 0,700 & Reliabel \\
\hline
\end{tabular}

Nilai reliabilitas butir pernyataan pada kuesioner masing-masing variabel yang sedang diteliti lebih besar dari 0,700 sehingga hasil ini menunjukkan bahwa butir kuesioner pada masing-masing variabel andal untuk mengukur variabelnya masing-masing.

\section{Pengujian Hipotesis dengan Menggunakan Analisis Jalur (Path Analysis)}

- Tahap 1: Merumuskan Persamaan Struktural Menentukan model diagram jalurnya berdasarkan paradigma hubungan variabel seperti gambar di bawah ini:

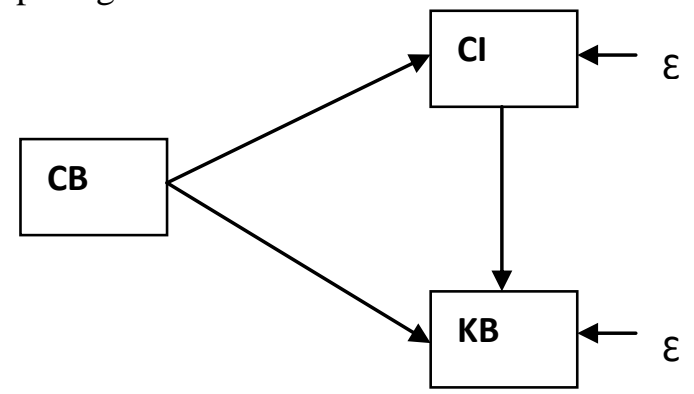

Gambar 2 Model Diagram Jalur
Dari model di atas maka dapat dibuat persamaan struktural sebagai berikut:

$\mathrm{Y}=\rho_{\mathrm{Y} 2 . \mathrm{X}} \mathrm{X}+\rho_{\mathrm{Y} 2 . \mathrm{Y} 1} \mathrm{Y}_{1}+\varepsilon$

Dimana:

$\mathrm{KB} \quad=$ Keputusan Berkunjung $\left(\mathrm{Y}_{2}\right)$

$\mathrm{CB}=$ City Branding (X)

$\mathrm{CI}=$ City Images $\left(\mathrm{Y}_{1}\right)$

$\varepsilon \quad=$ Kontribusi variabel lain (error)

$\rho_{\mathrm{Y} 1 \mathrm{X}}=$ Koefisien jalur dari $\mathrm{X}$ terhadap $\mathrm{Y}_{1}$

$\rho_{\mathrm{Y} 2 . \mathrm{X}}=$ Koefisien jalur dari $\mathrm{X}$ terhadap $\mathrm{Y}_{2}$

$\rho_{\mathrm{Y} 2 . \mathrm{Y} 1}=$ Koefisien jalur dari $\mathrm{Y}_{1}$ terhadap $\mathrm{Y}_{2}$

- Tahap 2: Membuat Diagram Jalur

Membuat diagram jalurnya sebagai berikut:

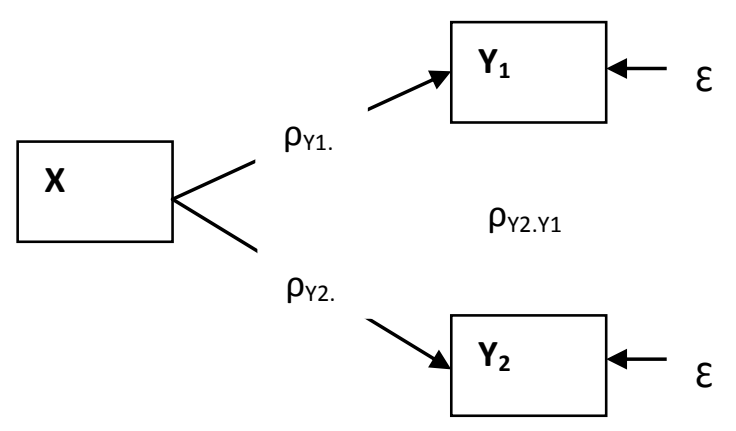

Gambar 3 Diagram Jalur dan Paradigma Penelitian

- Tahap 3: Konversi Skala

Sebelum diolah dengan analisis jalur, data dalam skala ordinal yang didapat dari kuesioner terlebih dahulu ditransformasi data dalam skala interval dengan menggunakan Method of Succesive (MSI). Pengolahan data ordinal menjadi interval dilakukan dengan program Microsoft Excel.

- Tahap 4 : Pengaruh antara City Branding (X) terhadap City Images (Y1)

Untuk memperoleh koefisien jalur, pertama-tama yang dilakukan adalah mencari koefisien korelasi. Dari hasil pengolahan pada SPSS diperoleh korelasi antar variabel bebas (X). Selanjutnya model jalur yang akan dicari untuk menjelaskan hubungan fungsional dari variabel city branding $(\mathrm{X})$ terhadap city images $\left(\mathrm{Y}_{1}\right)$ adalah sebagai berikut: $\mathrm{Y}_{1}=\rho_{\mathrm{Y} 1 . \mathrm{X}} \mathrm{X}+\varepsilon$

Dimana:

$\mathrm{Y}_{1} \quad=$ City Images $(\mathrm{Y} 1)$

$\mathrm{X}=$ City Branding $(\mathrm{X})$

$\varepsilon \quad=$ Kontribusi variabel lain (residu)

$\rho_{\mathrm{Y} 1 \mathrm{X}}=$ Koefisien jalur dari $\mathrm{X}$ terhadap $Y_{1}$.

Adapun output SPSS 19.0 sebagai berikut: 
Tabel 6 Koefisien Jalur City Branding (X)

\begin{tabular}{|c|c|c|c|c|c|}
\hline \multirow[t]{2}{*}{ Model } & \multirow{2}{*}{$\begin{array}{l}\text { Unstandarized } \\
\text { Coefficients } \\
\text { B }\end{array}$} & \multicolumn{3}{|c|}{$\begin{array}{c}\text { Std. } \\
\text { Coefficients }\end{array}$} & \multirow[b]{2}{*}{ Sig. } \\
\hline & & $\begin{array}{l}\text { Std. } \\
\text { Error }\end{array}$ & Beta & $\mathrm{t}$ & \\
\hline (Constant) & 3.782 & 1.531 & & 2.471 & 0.15 \\
\hline $\begin{array}{c}\text { City } \\
\text { Branding }\end{array}$ & .423 & 0.41 & .638 & 10.275 & .000 \\
\hline
\end{tabular}

Berdasarkan output di atas diperoleh koefisien jalur untuk setiap variabel sebagai berikut:

$$
\rho_{\mathrm{Y} 1 . \mathrm{X}} \mathrm{X}=0,638
$$

dimana nilai $\varepsilon=1-0,638=0,362$

Dengan demikian maka diperoleh persamaan jalur sebagai berikut:

$$
\mathrm{Y}=0,638 \mathrm{X}
$$

Jika digambarkan, persamaan di atas tampak sebagai berikut:

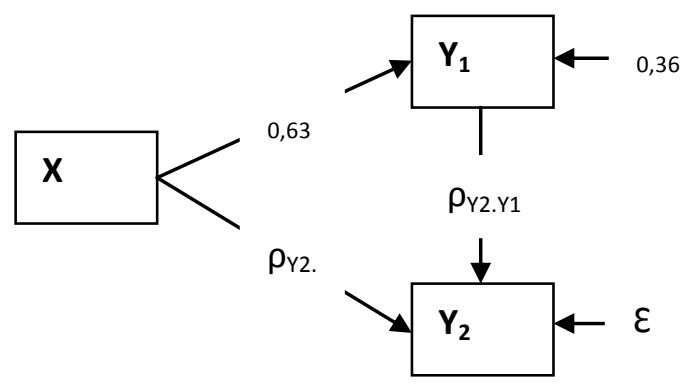

Gambar 4 Diagram Path

Setelah koefisien jalur diperoleh, maka besar pengaruh City Branding (X) terhadap City Image (Y1) dapat ditentukan dari hasil perkalian koefisien jalur terhadap matriks korelasi antara variabel sebab $\mathrm{X}$ dengan variabel akibat $\mathrm{Y}_{1}$.

$$
\begin{aligned}
\mathrm{R}_{\mathrm{XY1}}^{2} & =[0.638] \times[0.638] \\
& =0,407=40,7 \%
\end{aligned}
$$

Sedangkan besar koefisien jalur untuk faktor lain

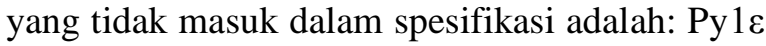
$=\sqrt{1-0,638}=0,602$

Atau dalam persentase besarnya pengaruh dari variabel lain yang tidak diamati adalah sebesar adalah sebesar $60,2 \%$.
- Tahap 5: Pengaruh City Branding (X) dan City Images $\left(\mathrm{Y}_{1}\right)$ Terhadap Keputusan Berkunjung $\left(\mathrm{Y}_{2}\right)$

Untuk melihat pengaruh dari city branding (X) dan city images $\left(\mathrm{Y}_{1}\right)$ Terhadap keputusan berkunjung $\left(\mathrm{Y}_{2}\right)$, akan digunakan analisis jalur (Path Analysis). Selanjutnya, model jalur yang akan dicari untuk menjelaskan hubungan fungsional dari variabel city branding (X) dan city images $\left(\mathrm{Y}_{1}\right)$ keputusan berkunjung $\left(\mathrm{Y}_{2}\right)$ adalah sebagai berikut:

Dimana:

$$
\mathrm{Y}=\rho_{\mathrm{Y} 2 . \mathrm{X}} \mathrm{X}+\rho_{\mathrm{Y} 2 . \mathrm{Y} 1} \mathrm{Y} 1+\varepsilon
$$

$\mathrm{Y}_{2} \quad=$ keputusan berkunjung (Y2)

$\mathrm{X}=$ city branding $(\mathrm{X})$

$\mathrm{Y}_{1} \quad=$ city images $(\mathrm{Y} 1)$

$\varepsilon \quad=$ Kontribusi variabel lain (error)

$\rho_{\mathrm{Y} 2 . \mathrm{X}}=$ Koefisien jalur dari $\mathrm{X}$ terhadap $\mathrm{Y}_{2}$

$\rho_{\mathrm{Y} 2 . \mathrm{Y} 1}=$ Koefisien jalur dari $\mathrm{Y}_{1}$ terhadap $\mathrm{Y}_{2}$

Dengan menggunakan Software SPSS 19.0, diperoleh koefisien jalur sebagai berikut:

Tabel 7 Koefisien Jalur City Branding (X) dan City Images $\left(\mathrm{Y}_{1}\right)$

\begin{tabular}{cccccc}
\hline Model & $\begin{array}{r}\text { Unstandarized } \\
\text { Coefficients }\end{array}$ & \multicolumn{5}{c}{$\begin{array}{c}\text { Std. } \\
\text { Coefficients }\end{array}$} & $\begin{array}{l}\text { Std. } \\
\text { E }\end{array}$ & Error & Beta & t & Sig. \\
& & & & & \\
\hline $\begin{array}{c}\text { (Constant) } \\
\text { City } \\
\text { Branding }\end{array}$ & 4.239 & 1.437 & & 2.951 & 004 \\
$\begin{array}{c}\text { City } \\
\text { Images }\end{array}$ & .225 & 0.49 & .339 & 4.577 & .000 \\
& .443 & .074 & .442 & 5.974 & .000 \\
\hline
\end{tabular}

Berdasarkan output di atas diperoleh koefisien jalur untuk setiap variabel sebagai berikut:

$$
\begin{aligned}
& \mathrm{P}_{\mathrm{Y} 2 . \mathrm{X}}=0,339 \\
& \mathrm{P}_{\mathrm{Y} 2 . \mathrm{Y} 1}=0,442
\end{aligned}
$$

$$
\text { Dimana nilai } \varepsilon=1-0,339-0,442=
$$

Dengan demikian maka diperoleh persamaan jalur sebagai berikut: $\mathrm{Y}=0,339 \mathrm{X}+0,442 \mathrm{Y}_{1}$

Berdasarkan analisis di dua sub struktur di atas, maka secara keseluruhan dapat digambarkan model hubungan yang terjadi sebagai berikut: 


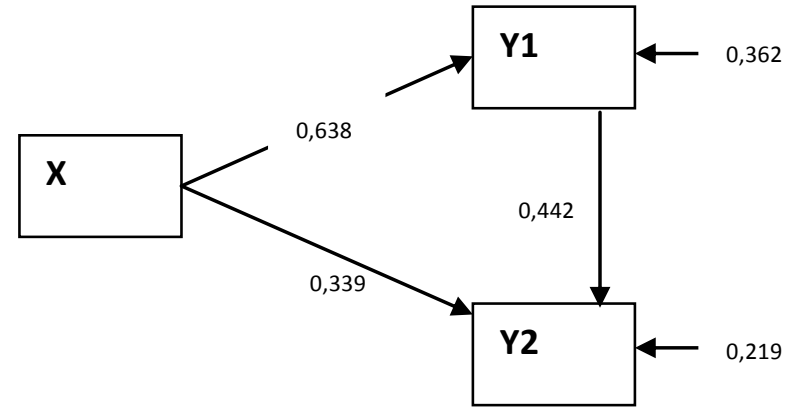

Gambar 5 Diagram Dekomposisi

\section{Menguji Kesesuaian antar Model Jalur}

Berdasarkan alisis pada dua sub struktur di atas, maka secara keseluruhan dapat digambarkan model hubungan yang terjadi sebagai berikut:

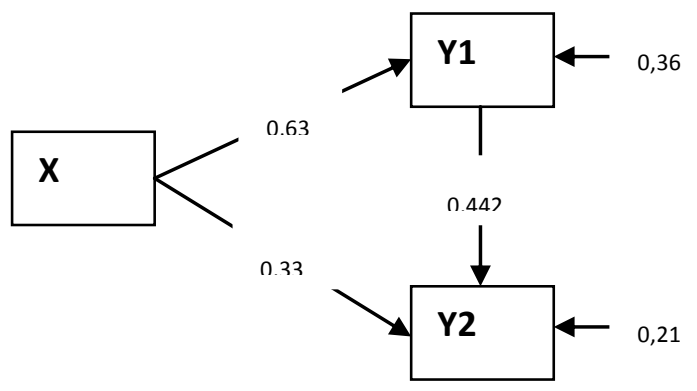

Gambar 6 Model Diagram Jalur

Dari gambar di atas dapat dijelaskan pengaruh langsung dan pengaruh tidak langsung yang terjadi antar variabel sebagai berikut:

Pengaruh langsung $\mathrm{X}$ terhadap $\mathrm{Y}_{1}$

$$
\begin{aligned}
& =\mathrm{P}_{\mathrm{Y} 1 . \mathrm{X}} \cdot \mathrm{P}_{\mathrm{Y} 1 . \mathrm{X}} \\
& =0,638 \times 0,638 \\
& =0,407 \text { atau } 40,7 \% \text { (signifikan) }
\end{aligned}
$$

Pengaruh langsung $\mathrm{X}$ terhadap $\mathrm{Y}_{2}$

$$
\begin{aligned}
& =\mathrm{P}_{\mathrm{Y} 2 \cdot \mathrm{X}} \cdot \mathrm{P}_{\mathrm{Y} 2 \mathrm{X}} \\
& =0,339 \times 0,339 \\
& =0,115 \text { atau } 11,50 \% \text { (signifikan) }
\end{aligned}
$$

Pengaruh langsung $\mathrm{Y}_{1}$ terhadap $\mathrm{Y}_{2}$

$$
\begin{aligned}
& =P_{Y 2 . Y 1} \cdot P_{Y 2 . Y 1} \\
& =0,442 \times 0,442 \\
& =0,195 \text { atau } 19,50 \% \text { (signifikan) }
\end{aligned}
$$

\begin{tabular}{|c|c|c|c|c|c|}
\hline Variabel & $\begin{array}{l}\text { Koefisien } \\
\text { Jalur }\end{array}$ & $\begin{array}{l}\text { Pengaruh } \\
\text { Langsung }\end{array}$ & $\begin{array}{l}\text { Penga } \\
\text { Langs } \\
\mathrm{X} \\
\end{array}$ & $\begin{array}{l}\text { Cidak } \\
\mathrm{Y}_{1} \\
\end{array}$ & $\begin{array}{l}\text { Total } \\
(\%)\end{array}$ \\
\hline $\mathrm{X}$ & 0,339 & $11,5 \%$ & - & $9,6 \%$ & 21,10 \\
\hline $\mathrm{Y}_{1}$ & 0,442 & $19,5 \%$ & $9,6 \%$ & - & 29,10 \\
\hline \multicolumn{5}{|c|}{ Total Pengaruh } & 50,20 \\
\hline
\end{tabular}

Pengaruh tidak langsung $\mathrm{X}$ terhadap $\mathrm{Y}_{2}$ melalui

$$
\begin{aligned}
\mathrm{Y}_{1} & =\mathrm{P}_{\mathrm{Y} 1 . \mathrm{X}} \cdot \mathrm{P}_{\mathrm{Y} 2 . \mathrm{X}} \cdot \mathrm{P}_{\mathrm{Y} 2 . \mathrm{Y} 1} . \\
& =0,638 \times 0,339 \times 0,442 \\
& =0,096 \text { atau } 9,6 \% \text { (Signifikan) }
\end{aligned}
$$

Secara ringkas pengaruh $\mathrm{X}$ dan $\mathrm{Y}_{1}$ terhadap $\mathrm{Y}_{2}$ disajikan dalam tabel berikut ini.

Tabel 8 Ringkasan Besaran Pengaruh Berdasarkan Koefisien Jalur

\section{Pembahasan Hasil Uji Hipotesis}

- Hasil Uji Hipotesis 1

Hipotesis ini bertujuan untuk menguji pengaruh City Branding terhadap City Image. Hasil uji hipotesis menggunakan analisis jalur (path analysis) menemukan bahwa variabel City Branding mempunyai pengaruh terhadap City Image sebesar 40,7\% $\left(=0,638^{2} \times 100 \%\right)$ berdasarkan data pada tabel VI. Dengan demikian hipotesis pertama didukung dan dapat disimpulkan bahwa city branding Kabupaten Purwakarta mempengaruhi city image Kabupaten Purwakarta (tingkat signifikansi sebesar 0,00). Penemuan ini sesuai dengan hasil penelitian oleh Jannah., Arifin \& Kusumawati (2014) yang menemukan bahwa city branding berpengaruh signifikan terhadap city image. Hasil temuan tersebut juga sesuai dengan hasil penelitian Wandari., Kumandji \& Kusumawati (2014). Dengan demikian untuk meningkatkan city image Kabupaten Purwakarta sebagai salah satu destinasi wisata maka harus diimbangi juga dengan peningkatan city branding Kabupaten Purwakarta yang memang saat ini dikenal dengan "Purwakarta Istimewa"

- Hasil Uji Hipotesis 2

Hipotesis ini bertujuan untuk menguji pengaruh City Branding terhadap Keputusan Berkunjung. Hasil uji hipotesis menggunakan analisis jalur (path analysis) menemukan bahwa variabel City Branding mempunyai 
pengaruh yang signifikan terhadap Keputusan Berkunjung sebesar $11,50 \% \quad\left(=0,339^{2} \mathrm{x}\right.$ $100 \%$ ). Dengan demikian hipotesis kedua didukung dan dapat disimpulkan bahwa city branding Kabupaten Purwakarta mempengaruhi keputusan untuk berkunjung wisatawan ke Kabupaten Purwakarta tersebut (tingkat signifikansi sebesar 0,00). Penemuan ini juga sesuai dengan hasil penelitian oleh Jannah., Arifin \& Kusumawati (2014) yang menemukan bahwa city branding berpengaruh signifikan terhadap keputusan berkunjung. Hasil temuan tersebut juga sesuai dengan hasil penelitian Wandari., Kumandji \& Kusumawati (2014). Dengan demikian diharapkan ada peningkatan dari sisi city branding mengenai Kabupaten Purwakarta sebagai tempat yang "istimewa" untuk dikunjungi sehingga diharapkan akan mendongkrak jumlah kunjungan wisatawan ke Kabupaten Purwakarta.

\section{- Hasil Uji Hipotesis 3}

Hipotesis ini bertujuan untuk menguji pengaruh City Image terhadap Keputusan Berkunjung. Hasil uji hipotesis menggunakan analisis jalur (path analysis) menemukan bahwa variabel City Image mempunyai pengaruh yang signifikan terhadap Keputusan Berkunjung sebesar $19,50 \% \quad\left(=0,442^{2} \mathrm{x}\right.$ $100 \%)$. Dengan demikian hipotesis ketiga didukung dan dapat disimpulkan bahwa city image kabupaten Purwakarta mempengaruhi keputusan untuk berkunjung wisatawan domestik ke Kabupaten Purwakarta tersebut. Penemuan ini juga sesuai dengan hasil penelitian oleh Jannah., Arifin \& Kusumawati (2014) menemukan bahwa city image berpengaruh walau tidak signifikan terhadap keputusan berkunjung. Hasil temuan tersebut juga sesuai dengan hasil penelitian Wandari., Kumandji \& Kusumawati (2014). Dengan demikian walaupun pengaruh city image terhadap keputusan berkunjung tidak terlalu besar tetapi tetap menjadi perhatian khusus bagi pemerintah Kabupaten Purwakarta untuk meningkatkan city image Kabupaten Purwakarta sebagai salah satu destinasi wisata yang diminati wisatawan sehingga diharapkan dapat mendongkrak juga keinginan dan keputusan berkunjung ke Kabupaten Purwakarta.

\section{KESIMPULAN， KETERBATASAN DAN SARAN \\ Simpulan}

Berdasarkan hasil analisis dan pembahasan sebelumnya, dapat diambil beberapa kesimpulan yang menjadi jawaban atas tujuan penelitian yang telah ditetapkan.

1. City Branding (X) berpengaruh signifikan terhadap City Images $\left(\mathrm{Y}_{1}\right)$ dengan persentase pengaruh sebesar $40,7 \%$.

2. City Branding (X) berpengaruh signifikan terhadap Keputusan Berkunjung $\left(\mathrm{Y}_{2}\right)$ dengan persentase pengaruh sebesar 11,5\%.

3. City Images $\left(\mathrm{Y}_{1}\right)$ berpengaruh terhadap Keputusan Berkunjung $\left(\mathrm{Y}_{2}\right)$ dengan persentase pengaruh sebesar 19,5\%.

4. City Branding $(\mathrm{X})$ dan City Images $\left(\mathrm{Y}_{1}\right)$ berpengaruh terhadap Keputusan Berkunjung $\left(\mathrm{Y}_{2}\right)$ dengan persentase pengaruh sebesar 50,98\%.

5. City Branding (X) berpengaruh signifikan terhadap Keputusan Berkunjung $\left(\mathrm{Y}_{2}\right)$ melalui City Images $\left(\mathrm{Y}_{1}\right)$ dengan persentase pengaruh sebesar $9,6 \%$.

\section{Keterbatasan; Saran Bagi Penelitian Mendatang, dan Saran Bagi Pemerintah Kabupaten Purwakarta.}

Beberapa keterbatasan penelitian ini dapat dinyatakan sebagai berikut: penelitian ini hanya dilakukan di beberapa tempat wisata yang ada di Kabupaten Purwakarta dan penelitian ini hanya mengidentifikasi faktor city branding pada city image dan keputusan berkunjung wisatawan khususnya wisatawan domestik. Dengan demikian, untuk penelitian mendatang beberapa hal yang dapat disarankan. Pertama, lakukan studi yang lebih luas untuk berbagai tempat wisata yang ada di Kabupaten Purwakarta.

Kedua, jumlah sampel dalam penelitian ini memang sudah memenuhi kriteria, tetapi akan lebih baik sampel dapat ditambahkan lebih banyak sehingga hasil dari pengujian hipotesis dapat digeneralisasikan.

Ketiga, yang menjadi responden penelitian ini masih terbatas pada wisatawan lokal atau domestik, diharapkan untuk penelitian lebih lanjut dapat diperluas kepada wisatawan mancanegara.

Bagi pihak pemerintah Kabupaten Purwakarta, sebaiknya lebih mengoptimalkan kegiatan komunikasi pemasaran secara terintegrasi (integrated marketing communication) seperti advertising, interactive marketing, public relation termasuk juga sosial 
media agar segala bentuk keunikan dan keunggulan tempat wisata maupun event-event tertentu yang diselenggarakan oleh penduduk maupun pemerintah Kabupaten Purwakarta dapat disampaikan mencapai sasaran target audience secara tepat sehingga mampu memotivasi lebih banyak target audience yaitu wisatawan baik lokal maupun mancanegara untuk berkunjung dan merekomendasikan Kabupaten Purwakarta sebagai salah satu destinasi wisata favorit sehingga diharapkan akan terjadi peningkatan PAD (pendapatan asli daerah). Tentu saja hal ini bisa terlaksana optimal jika ditopang juga dengan adanya peningkatan city branding dan city image Kabupaten Purwakarta. City branding hendaknya terus dipublikasikan kepada masyarakat agar masyarakat memahami makna dari brand kabupaten Purwakarta yaitu "Purwakarta Istimewa". Selain itu, pemerintah kabupaten Purwakarta sebaiknya meningkatkan citra image Kabupaten Purwakarta yang lebih positif agar tercipta citra yang baik terhadap Kabupaten Purwakarta di benak wisatawan.

\section{DAFTAR PUSTAKA}

Anholt, S. (2007). Competitive Identity: The New Brand Management for Nation, Cities, and Regions. Palgrave macmillan, London.

Chaerani, R. Y. (2011). Pengaruh City Branding Terhadap City Image (Studi Pencitraan Kota Solo: "The Spirit of Java"). Jurnal Universitas Sultan Ageng Tirtayasa

Christianto, A. I. Memetakan Potensi Kabupaten Bondowoso Dalam Merancang Strategi City Branding. Jurnal Fakultas Ilmu Sosial dan Ilmu Politik Universitas Brawijaya

Dharmmesta, B.S. \& Handoko, H.(1982), Manajemen Pemasaran: Analisis Perilaku Konsumen. Yogyakarta: PBFE Universitas Gadjah Mada.

Ekinci, Y. (2006). Destination Personality: An Apllication Of Brand Personality To Tourism Destination. Journal of Travel Research, 45(2), 127-139.

Ferdinand, A. (2002). Pengembangan Minat Beli Merek Ekstensi.Semarang Badan Penerbit Universitas Diponegoro

Ghozali, D. M. (2005). Communication Measurement. Bandung: Simbiosa Rekatama Media.

Ghozali, I. (2011). Aplikasi Analisis Multivariate Dengan Program SPSS. Semarang: Badan Penerbit Universitas Dipenogoro.
Jannah, B, dkk. (2014). Pengaruh City Branding dan City Image Terhadap Keputusan Berkunjung Wisatawan ke Banyuwangi. Jurnal Admistrasi Bisnis. Vol. 17. No. 1 Desember 2014.

Kavaratzis, M. (2004). City and Their Brands: Lessons from Corporate Branding. Journal of Place branding and public diplomacy Vol.5,1,26-37. Palagrace Macmillan.

Kavaratzis. (2008). From City Marketing to City Branding, An Interdisciplinary Analysis with Reference to Amsterdam, Budapest and Athens. Dissertations: University of Groningen.

Kevin, L. K. (1998). Strategic Brand Management: Building, Measuring and Managing Brand Equity. NJ: Prentice Hall.

Kotler, P., \& Armstrong, G. (2004). Principles Of Marketing. Tenth Edition, Pearson Prentice Hall , New Jersey

Kotler, P., \& Kevin, L. K. (2009). Manajemen Pemasaran (Edisi 13. Jilid 1). Jakarta: Erlangga.

Kotler, P. (2005). Manajemen Pemasaran Jilid 1. Jakarta: PT. Indeks kelompok Gramedia.

Riduwan \& Engkos, A. K. (2011). Cara Menggunakan dan Memaknai Path Analysis (Analisis Jalur). Bandung: Alfabeta.

Riyadi (2009). Fenomena City Branding Pada Era Otonomi Daerah. Jurnal Bisnis Dan Kewirausahaan. Vol.5 No.1 Hal-1.

Sari, M. I. (2015). Analisis Implementasi City Branding. Jurnal Ekonomi Jurusan Manajemen Konsentrasi Pemasaran Fakultas Ekonomi Dan Bisnis Universitas Brawijaya, Malang.

Sugiyono. (2010). Metode Penelitian Bisnis. Bandung: Alfabeta.

Wandari, dkk. (2014). Pengaruh City Branding Kota Wisata Batu. Jurnal administrasi Bisnis (JAB) Vol. 16 No. 1.

Yananda, S. (2014). Branding Tempat: Membangun Kota, Kabupaten, dan Provinsi Berbasis Identitas. Makna Informasi, Jakarta.

http://www.detiknews.com http://www.hipwee.com https://ilmumanajemenpemasaran.wordpress.com http:// www.indonesia-investment.com http://www.nativeindonesia.com http://perpustakaanmanajemen.blogspot.co.id https://id.wikipedia.org 